Int. J. Morphol.,

36(3):931-936, 2018

\title{
Seven Segmental Pedicles at the Porta Hepatis
}

\author{
Siete Pedículos Segmentarios en la Porta Hepatis
}

César Augusto Durand López ${ }^{1}$ \& Daniela Yecenia Ramos Serrano ${ }^{2}$

DURAND, L. C. A. \& RAMOS, S. D. Y. Seven segmental pedicles at the porta hepatis. Int. J. Morphol., 36(3):931-936, 2018.

SUMMARY: We wanted to know how many segmental portal branches were born from the primary branches of the hepatic portal vein in the porta hepatis, in order to determine the number of portal segments in human liver. We studied 286 human livers, age groups ranging from fetuses to octogenarians, both sexes and all races, using dissection, colored acrylic injection and reconstituted tomographic images. We found the porta hepatis channel formed by each and every portal segment; we found seven segmental terminal pedicles for seven portal segments, three planes of vertical and three planes of horizontal portal fissures. There are seven terminal portal pedicles that are formed in the porta hepatis from the right and left branches of the hepatic portal vein. The only variation was portal branch V emerging from the right branch in $79 \%$ of cases or from the left branch in $21 \%$. The definition of hepatic portal segment is: Portion of parenchyma irrigated by terminal branches of the portal vein and the hepatic artery proper, isolated from the other segments by planes of portal fissures and forms the parenchymal channel of the porta hepatis where it receives its vascularization. We propose a new and simple portal segmentation based on the previous definition.

KEY WORDS: Seven segmental pedicles; Seven portal segments.

\section{INTRODUCCIÓN}

Several published studies (Botero \& Strasberg; 1998; Fasel et al., 1998; Ishibashi et al., 2001; Fischer et al., 2002; Rieker et al., 2003; Rutkauskas et al., 2006; Castorina, 2014) agreed on the need to carry out investigations that simply describe the hepatic anatomy and unify the anatomical terminology in relation to the liver. The confusion reached its highest point when the "Terminology Committee of the International Hepato-Pancreato-Biliary Association" (Strasberg et al., 2000) came to take into account agreements on anatomical terminology of the liver based in the existing literature, that is to say, based on drawings and not on anatomical research, for this reason the confusion continues. Indeed, we see in texts of human anatomy and books of surgical specialties the same drawings pretending to explain the anatomy of the liver.

Knowing that the hepatic portal vein has a hegemonic role in liver irrigation, we wanted to know the number of segmental (terminal) portal branches to determine the number of portal segments. We did not find in the medical literature any information about the characteristics and definition of "portal segment", for all these reasons we decided to investigate the vascular anatomy of the liver.

\section{MATERIAL AND METHOD}

We studied 286 human livers (A05.8.01.001) of different ages (from fetuses to octogenarians), races and sex, using the following techniques: 150 livers were injected with colored acrylic in the hepatic portal vein (A12.3.12.001), hepatic artery proper (A12.2.12.029), common hepatic duct (A05.8.01.061), inferior vena cava (A12.3.09.001) and through it to the hepatic veins (A12.3.09.005), were then immersed in a solution of $10 \%$ hydrochloric acid to remove the parenchyma to study injected anatomical elements; 50 were dissected in fresh and 30 were dissected after fixing them with formalin using the knowledge that gave the acrylics; we studied 56 cases of three-dimensional tomographic reconstructions of patients randomly selected using the concepts learned through dissections. We use Terminologia Anatomica (FCAT, 2001).

\section{RESULTS}

Each segment was part of the parenchymal canal of the Porta hepatis (A05.8.01.016) (Fig. 1) in all dissected livers (230). We found 7 vascular pedicles in all cases.

${ }^{1}$ Surgeon at the "José Casimiro Ulloa" Emergency Hospital and Professor of Human Anatomy, "Ricardo Palma" University, Lima,Perú.

${ }^{2}$ Medical Legist at the "Morgue del Callao", Professor of Human Anatomy at the "Federico Villarreal" National University, University of Piura and the Southern Scientific University, Lima-Perú. 
The segmental branches I, II, III and IV emerged from the left portal vein (A12.3.12.005), the branches V, VI and VII emerged from the right portal vein (A12.3.12.002) in 226 cases (79 \%). The segmental portal branches I, II, III, IV and V emerged from the left portal vein, the branches VI and VII emerged from the right portal vein in 60 cases $(21 \%)$, this last one due to the segmental portal branch $\mathrm{V}$ emerged from the left portal vein (Fig. 2). In no case did we find an eighth segmental branch.

The hepatic portal vein was divided into right and left (primary branches) at the porta hepatis, then each one originated terminal secondary branches for each segment, attracting the arterial and biliary formed seven segmental vascular pedicles, these pedicles were also located in the porta hepatis, below the hepatic return veins. The left portal vein presented a transverse part (A12.3.12.006) and another anterior or umbilical part (A12.3.12.008) both formed an angle of 90 degrees of antero medial sinus. The transverse part (12 $\mathrm{mm}$ in diameter) had a length of $3-4 \mathrm{~cm}$; the umbilical part (10 $\mathrm{mm}$ in diameter) was $1-2$ $\mathrm{cm}$ in length. The left branch initiated the origin of the segmental branches when giving the branch for segment I (A05.8.01.044) in $100 \%$ of cases (2 $\mathrm{mm}$ in diameter), accompanied in $60 \%$ by a subsegmental branch of the right portal vein or in $5 \%$ of the hepatic portal vein; the single branch for segment II (A05.8.01.039) emerged in $100 \%$ of cases (4 mm in diameter) from the left portal vein angle, this branch formed a 135 degrees posterior sinus angle with the transverse part of the left portal vein. The branch for segment III (A05.8.01.040) $(6 \mathrm{~mm}$ diameter) and two or three sub-segmental branches were born to the left of the terminal bulb of the umbilical part of the left portal vein. The branch for segment IV (A05.8.01.042) (6 mm diameter) was born to the right of the terminal bulb of the umbilical part of the left portal, two or three subsegmental branches for segment IV were born to the right of the mentioned bulb or on the upper edge of the transverse part of the left portal vein. The branch for segment $\mathrm{V}$ (A05.8.01.047) (10 mm diameter) emerged from the left portal vein in $21 \%$ of cases, it emerged from the right portal vein in $79 \%$; this segmental branch, after deepening $2 \mathrm{~cm}$ in its segmental parenchyma gave anterior, lateral, posterior and medial branches distributed between the right portal fissure (A05.8.01.036) and the main portal fissure (A05.8.01.035) from the lower border of the liver (A05.8.01.024) to the inferior vena cava from behind; the medial branches reached higher in the hepatic dome. The $\mathrm{V}$ branch is the only one existing for the right medial division (A05.8.01.046) of the liver. The right branch of the hepatic portal vein is $16 \mathrm{~mm}$ in diameter and $1-3 \mathrm{~cm}$ in length; it originated the branch for segment
VI (A05.8.01.050) $(6 \mathrm{~mm})$ in $100 \%$ of cases and the branch for segment VII (A05.8.01.051) (8 mm) in $100 \%$ of cases at the right end. The segmental portal branches that were accompanied by smaller caliber subsegmental were those for segments I, III and IV; segments II, V, VI and VII did not present subsegmental branches (Fig. 3).

The terminal irrigation of each segment with the consequent absence of communication between them originated the existence of planes of separation or fissures. Three vertical portal fissures and three horizontal portal fissures were observed. The vertical ones were: 1) The umbilical fissure (A05.8.01.034), located in the left part of the liver, separated left lateral division from left medial division (segments II-III from segment IV respectively on the diaphragmatic surface and segments II-III from segments I-IV on the visceral surface). 2) The main fissure separated both parts of the liver when the segmental branch $\mathrm{V}$ was born from the right portal vein (segment IV from segment $\mathrm{V}$ respectively on the diaphragmatic surface and on the anterior portion of the visceral surface). 3) The right fissure separated the right medial division from the right lateral division when the portal branch $\mathrm{V}$ was born from the right portal vein, when it was born from the left portal vein, this fissure acted as the main fissure and separated a huge left part from a small right part of the liver (It separated segment V from segments VI-VII respectively on the diaphragmatic surface and segments I-V from segments VI-VII on the visceral surface). The plane of the umbilical fissure tilted 50 degrees to the left relative to the sagittal plane of the liver; the main portal fissure tilted 30 degrees to the left relative to the sagittal plane of the liver; the right portal fissure tilted 60 degrees to the right relative to the sagittal plane of the liver. The right fissure contained the upper (A12.3.09.006), middle, and lower right hepatic veins; the main fissure contained the intermediate vein (A12.3.09.007); the umbilical fissure did not contain the left hepatic vein (A12.3.09.008), this vein has intrasegmental pathway in segments III and II. The main fissure divided the liver into right (A05.8.01.045) and left (A05.8.01.037) parts, the umbilical fissure divided the left part into left lateral division (A05.8.01.038) (including portal segments II and III) and left medial (segment IV) division (A05.8.01.041); the right fissure divided the right part into a right medial division (A05.8.01.046) (segment $\mathrm{V}$ only) and a right lateral division (A05.8.01.049) (segments VI and VII). Segment I was located on either side of the main fissure, behind and below the right and left medial divisions; we considered segment I within the left part of the liver because it always received its segmental branch from the left portal; its venous drainage was direct in the inferior vena cava. 
Horizontal fissures are located between segment II and III in the left lateral division; between the upper face of segment I and the base of the posterior half of segments IV and $\mathrm{V}$ in the right and left medial divisions; between segments VI and VII in the right lateral division; these three fissures did not contain return veins.

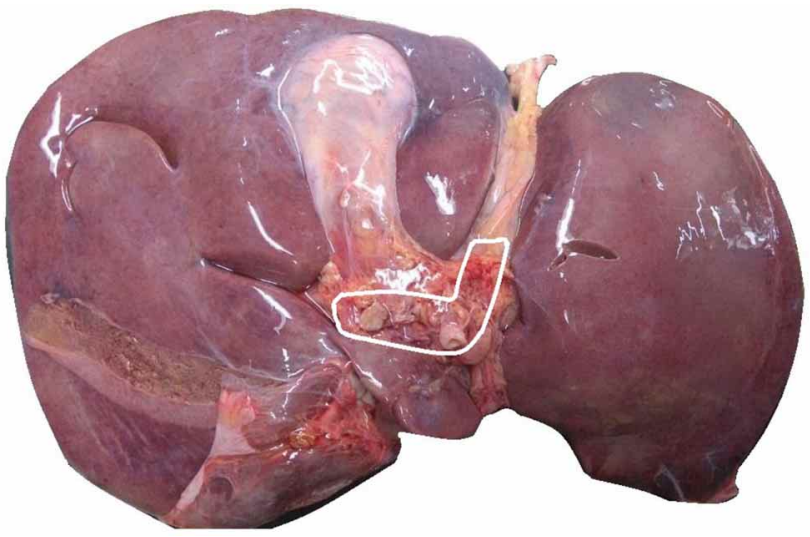

Fig. 1. Visceral surface of the liver, the Porta hepatis has been demarcated.

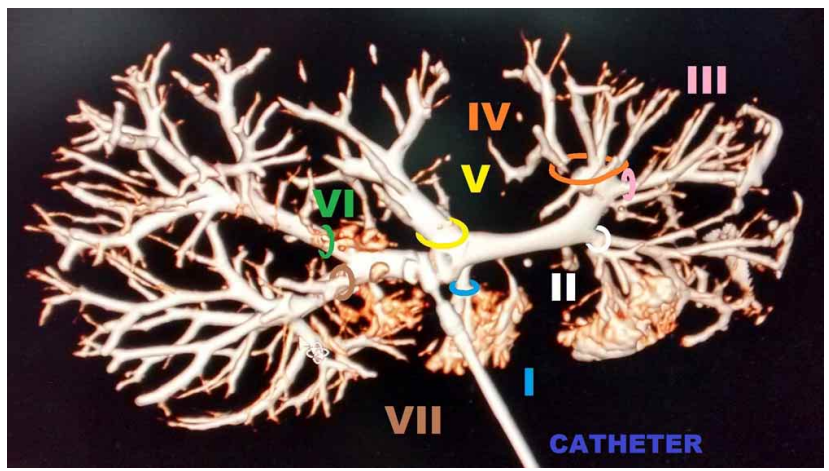

Fig. 2. Tomographic image of hepatic portal vein. We put rings at the emergency of each one of the seven portal pedicles. Note that branch I, II, III, IV and V emerge from left portal vein, branches VI and VII emerge from right portal vein (21\% of cases); the branch $\mathrm{V}$ gives anterior, lateral, posterior and medial tertiary branches. We never saw an eight branch emerging from any primary portal branch at the porta hepatis.

Fig. 4. Visceral surface of liver injected with acrylic. The primary branches of the hepatic portal vein are light blue; the arteries are red, the bile duct green. Secondary portal branches (segmental and terminal) have the following colors: Segment I light blue, II white, III in pink, IV orange, V yellow, VI green and VII brown. The dissection of the Porta hepatis was expanded to see the birth and the course of the segmental portal branches.
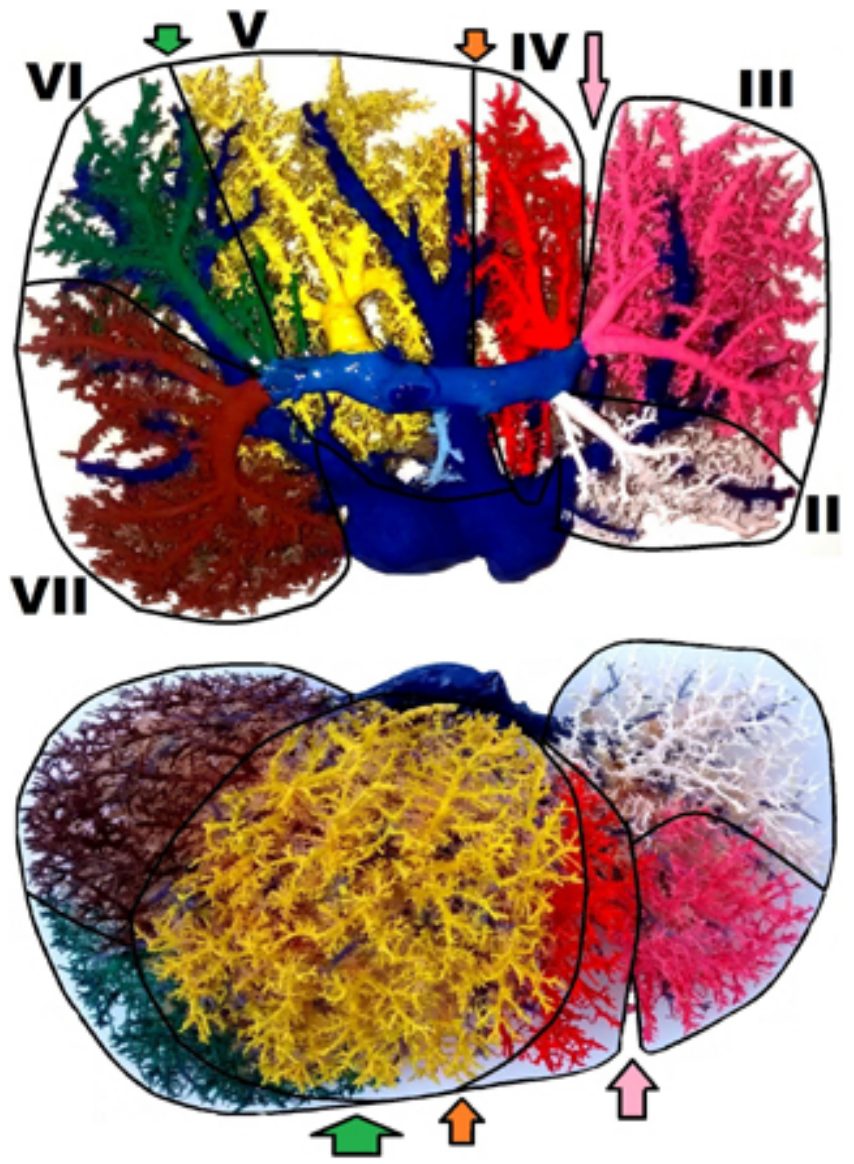

Fig. 3. Acrylics of the liver, the upper figure is the visceral surface, the lower is the diaphragmatic surface. In the visceral surface we can see the primary branches (blue) of the portal vein (left and right) giving the secondary branches (segmental and terminal). For segment I light blue, II white, III pink, IV orange, V yellow, note that branch $\mathrm{V}$ gives anterior, lateral, posterior and medial tertiary branches that are distributed between segment IV to the left and segments VI-VII to the right. It is the only branch for the right medial division, there is no segment VIII; Segment VI in green and segment VII in brown. The diaphragmatic surface shows the same colors. The pink arrows point to the umbilical fissure, the oranges point to the main fissure, and the green arrows to the right fissure. Note that the left hepatic vein has an intrasegmental course; the umbilical fissure does not contain any return vein.

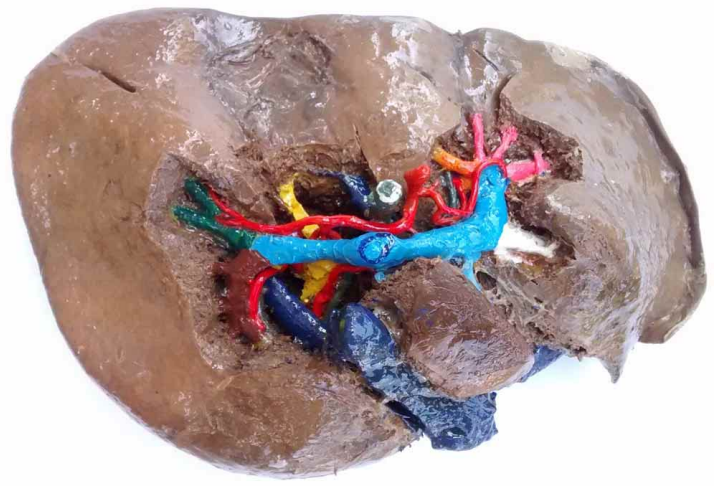


The size of the hepatic parts varied according to where the segmental branch V was born. When this branch emerged from the right portal vein, the fissure that separated the right and left parts of the liver was the main fissure; this went from the fossa for gallbladder (A05.8.01.0135) in a straight line to the left edge of the inferior vena cava. When the segmental branch $\mathrm{V}$ emerged from the left portal vein, segment V shaped the left part of the liver, in these cases the right fissure (It went from an intermediate point between the right border of the gallbladder and the right angle of the liver to the right edge of the inferior vena cava following a curved path of right convexity) divided the liver into a small right part and a large left part.

\section{DISCUSSION}

The need to coordinate the anatomical nomenclature of the liver was expressed by Botero \& Strasberg, who opined "A major obstacle to consistent terminology for liver anatomy and resections has been that American and French anatomists have divided the left side of the liver through different plans", we believe this difference is due to the absence of a clear definition of what a hepatic portal segment is. Fasel et al. recommended "radiologic determination of portal venous territories within the liver must be revised" these determinations must be supported by serial liver dissections. Hata et al. (1999) opined "Therefore, the three hepatic veins (RHV, SHV, and MHV) often did not aid the identification of the liver segments in the region. Consequently, the less than ideal combinations of irregular configurations of the portal and hepatic venous systems suggest that the later posterior segments cannot be conclusively identified anatomically in 30-40 \% of cases. Other means of identification, such as the conventional proportional manner (the upper and lower halves of the posterior sector roughly correspond to S6 and S7) may be required". On this view we must remember the right hepatic veins (occupy the right fissure) has laterally the right lateral division with segments VI and VII and medially, till the intermediate hepatic vein that occupies the main fissure, the right medial division with the segment $\mathrm{V}$ as unique component; the implantation of falciform ligament (A10.1.02.303) is medially to the intermediate hepatic vein, it indicates the umbilical fissure, plane of separation between the left lateral division (segments II and III) and the left medial division (segment IV). We must remember the left hepatic vein has intrasegmental course (III-II) and does not occupy the umbilical fissure, in addition, the planes of vertical fissures have different inclination Strasberg et al. in "The Brisbane 2000 Terminology of Liver Anatomy and Resections" gave importance to the anatomy-resection relationship, not anatomy per se. They said they had no responsibility for the investigation of the liver anatomy or for anatomical disputes. The terminology was based on accepted anatomy, intended to be consistent but based on inconsistent knowledge. It had to be based on the vascular anatomy if it wanted an anatomical and surgical description. Despite these agreements, the confusion continues, we believe it is due to the lack of a clear concept of what a portal segment is. Castorina said "The International Anatomical Terminology tries to unify the terminology of liver anatomy, making it a living language. The single, worldwide-accepted classification of the liver still does not exist. In fact, definition of segments according to Couinaud's nomenclature is different from that of Goldsmith and Woodburne. Through this approach, we propose a new terminology, which considers the liver divided into five lobes and seven segments plus one caudate lobe". Each researcher has different results because his research does not start from defined anatomical concepts. When we talk about portal segmentation we talk about vascular concepts and we have to define the characteristics of a portal segment, we can't use the term lobe because it is a descriptive concept of surface anatomy. Shilal \& Tuli (2015) opined "The pattern of drainage in the right posterior lobe of liver varies considerably. According to the pattern of drainage of tributaries of right hepatic vein, the right hepatic vein was classified into type I, type II, type III and type IV". We think anatomy should be described clearly and simply.

The inadequacy of Couinaud's portal division was expressed by Ishibashi et al. who opined "Thus, there are obvious limitations in using each system to determine the liver segment. In the present study, it was found that Couinaud's liver was the most common type of segment of the liver". Fischer et al. in "Limits of Couinaud's liver segmentation: a quantitative computer-based three-dimensional analysis" said "Couinaud's method of dividing the liver into eight autonomous liver segments has been accepted as a good approximation. Nevertheless, the volume, position, and shape of these segments and their segmental borders show significant variability (37\%)". Rieker et al. said "Investigation according to Couinaud's classification...the assignment failed in 51 of 409 branches due to unexpected anatomy or software problems". Rutkauskas et al. concluded, "Our understanding and explanation of liver composition are still defined differently among anatomists, surgeons, and radiologists, thus not only confusing less experienced specialists, but also increasing probability of mistakes. The smallest parts of the liver are defined using Couinaud's segmentation system". In previous publications (Durand, 2016, 2017a,b 2018; Durand et al., 2017) we showed results of novel findings in vascularization of the liver. 
To identify portal segments using reconstituted images (Fig. 2) previously we must know the anatomy based on dissections. Soyer et al. (1995) stated "Variations in the intrahepatic portions of the hepatic and portal veins are frequently seen on helical CTAP scans." Fasel et al. in "Segmental anatomy of the liver: poor correlation with CT" said "The radiologic determination of portal venous territories within the liver must be revised". Baba (2000) in 192 patients, using CTAP images to identify portal venous variations presented mixed results, concluded "Variations of the intrahepatic portal vein can be recognized on CTAP imaging tomography-Portal vein, computed tomography". Oshiro \& Ohkohchi (2017) using three-dimensional (3D) preoperative concluded: "The fusion image enables us to easily visualize anatomical relationships among the hepatic arteries, portal veins, bile duct, and tumor in the hepatic hilum". We believe that radiological images interpret the anatomy which we know best by dissection (Durand, 2017 a,b; Durand et al.) Iqbal et al. (2017) presented a review where it exposes the current reality.

During liver dissections, the Porta Hepatis, which is known as the portal plate, hilar plaque, lower hepatic hilum or portal channel, took a great importance; it is a parenchymal channel located in the middle third of the visceral surface, arranged transversely, is limited by the right portal fissure and the umbilical portal fissure, is "L" shaped to the left, it has two parts: the transverse part and the anterior or umbilical part, the latter portion is located on the lower border of the anterior portion of the umbilical fissure. This channel is completely covered by peritoneum, which gives it an aspect of "peritoneal thickening" (Fig. 1); the Porta hepatis is formed by the edges of each and every one of the 7 portal segments, which arrive here to receive their terminal vascular pedicles, in this way, the anterior edge of segment I forms the posterior edge of the transverse part of the porta hepatis, both to the right and to the left of the advent of the hepatic portal vein, this relation allows segment I to receive its segmental vascular pedicle and other subsegmental branches from both branches of the hepatic portal vein.

The angle of approximately 90 degrees of medial anterior sinus, formed by the transverse part and the umbilical part of the porta hepatis, has as its outer edge the segmental apex of segment II which, by this close contact, receives a segmental pedicle and no subsegmental branch. The lateral border of the umbilical part of the porta hepatis is formed by the medial border of segment III, thus this border has a length of approximately $7 \mathrm{~cm}$, which facilitates this segment to receive its segmental vascular pedicle and two or three variable subsegmental branches. The medial border and canal bed of the umbilical part of the porta hepatis, as well as the anterior border and the channel bed of the left transverse part of the porta hepatis are formed by segment IV (Quadrate lobe, A05.8.01.029) allowing it to this segment receive its segmental vascular pedicle from the umbilical part of the porta hepatis, in addition to 3-4 subsegmental branches, which may emerge at the upper edge of the left transverse part or the umbilical part of the porta hepatis. The segment $\mathrm{V}$ provides a parenchymal apex of $1-1.5 \mathrm{~cm}$ to form the anterior edge and the channel bed of the porta hepatis, to the right $(79 \%)$ or to the left (21\%) of the arrival of the hepatic portal vein, however, in this small space, this segment receives the more bulky segmental pedicle, without subsegmental branches. The right end of the porta hepatis is formed with the apex of segment VI forward and the apex of segment VII backwards.

Formed this parenchymal channel, we find the following inside (Fig. 4): 1) The hepatic portal vein and the hepatic artery proper and / or its accessories; the common hepatic duct exits, the hepatic artery proper forward and to the left, the bile duct forward and to the right, the hepatic portal vein behind and in the middle of the inferior hepatic pedicle. 2) The primary branches of the hepatic portal vein are born: right portal vein and left portal vein. The primary arterial branches of the hepatic artery proper are born: right branch (A12.2.12.030) and left branch (A12.2.12.035). The right hepatic duct (A05.8.01.062) joins the left hepatic duct (A05.8.01.065) to form the common hepatic duct. 3) The left and right branches of the hepatic artery proper are anastomosed, any of these branches with an accessory artery that may reach to get anastomosed, either branch of the left gastric artery or the superior mesenteric artery or some other variant. 4) Secondary terminal branches emerge from the primary branches of both the portal vein and the hepatic artery proper. Venous branches and arterial branches come together to form seven vascular pedicles destined for seven portal segments; the segmental ducts of biliary drainage are attached to them, which form common trunks between two or three segments and then form the hepatic duct on each side. Thus formed each segmental pedicle by these three elements, enter their corresponding parenchymal territory by the border that forms the channel of the porta hepatis, that is, whatever the vascular origin all will take the final route provided. As we see, the Porta hepatis is the place of arrival and distribution of the elements of the inferior hepatic pedicle, the vascular architecture of the organ is defined here.

The segmental branches I, II, III and IV arise from the left portal vein and the segmental branches V, VI and VII of the right portal in $79 \%$ of cases; The left portal vein gives branches I, II, III, IV and V, the right portal gives branches VI and VII in $21 \%$. We always found seven segmental branches; the only variation was the origin of the segmental portal branch $\mathrm{V}$. 
The planes of the portal fissures are the result of the absence of anastomosis between the segmental vascular branches.

We define "Portal segment" as follows: (1) it is a portion of the hepatic parenchyma irrigated by terminal branches of the portal vein and hepatic artery proper, and drained by a bile duct, (2) separated from neighboring segments by fissure planes created by the absence of anastomosis between them, (3) each one contributes to form the parenchymal channel of the Porta hepatis where it receives its vascular pedicle.

We believe this definition should guide the liver segmentation, it always will lead us to find seven portal pedicles, for seven segments, from which our proposal of 7 portal segments is born: Segment I (posterior segment), segment II (left lateral segment), segment III (left anteriorlateral segment), segment IV (left medial segment), segment $\mathrm{V}$ (right medial segment), segment VI (right anterior-lateral segment) and segment VII (right posterior-lateral segment). The only variant is the origin of the portal branch for segment $\mathrm{V}$, in $79 \%$ it is born from the right portal and $21 \%$ from the left portal; this variant does not change the order of the segmental numbering (Fig. 3) as it does in the segmental numbering of Couinaud.

DURAND, L. C. A. \& RAMOS, S. D. Y. Siete pedículos segmentarios en la porta hepatis. Int. J. Morphol., 36(3):931-936, 2018.

RESUMEN: El objetivo de este trabajo consistió en conocer el número de ramas portales segmentarias que nacen de las ramas primarias de la vena porta hepática en la Porta hepatis, con la finalidad de determinar el número de segmentos portales en el hígado humano. Estudiamos 286 hígados, los grupos etarios fueron desde fetos hasta octogenarios, ambos sexos y todas las razas, usamos la disección en fresco, inyección de acrílico coloreado e imágenes tomográficas reconstituidas. El canal de la Porta hepatis estuvo formado por todos y cada uno de los segmentos portales, encontramos siete pedículos terminales segmentarios para siete segmentos portales, el pedículo portal para el segmento $\mathrm{V}$ nació de la porta derecha en $79 \%$ de casos y de la porta izquierda en $21 \%$, encontramos tres planos de fisuras portales verticales y tres horizontales. Existen siete pedículos segmentarios portales terminales que se forman en la Porta hepatis a partir de las ramas derecha e izquierda de la vena porta hepática. La única variación fue que la rama portal para el segmento $\mathrm{V}$ nació de la rama derecha en $79 \%$ de casos y de la rama izquierda en $21 \%$. Concluimos que la definición de segmento portal hepático es: Porción de parénquima irrigado por ramas terminales de la vena porta y la arteria hepática propia, aislada de los otros segmentos por planos de fisuras y que llega a conformar el canal parenquimal de la Porta hepatis donde recibe su vascularización. Proponemos una nueva y sencilla segmentación portal basada en la definición previa.

PALABRAS CLAVE: Siete pedículos segmentarios; Siete segmentos portales.

\section{REFERENCES}

Baba, Y.; Hokotate, H.; Nishi, H.; Inoue, H. \& Nakajo, M. Intrahepatic portal venous variations: demonstration by helical CT during arterial portography. J. Comput. Assist. Tomogr, 24(5):802-8, 2000.

Botero, A. C. \& Strasberg, S. M. Division of the left hemiliver in man--segments, sectors, or sections. Liver Transpl. Surg., 4(3):226-31, 1998.

Castorina, S. Review of the nomenclature of the liver anatomical and functional areas by three-dimensional volume rendering 64-multislice computed tomography. Proposal for an update of the terminology. Ital. J. Anat. Embryol., 119(3):169$79,2014$.

Durand, L. C. A. Hígado, 7 Segmentos Portales. Bases Anatómicas para las Hepatectomías. Beau Bassin, Editorial Académica Española, OmniScriptum Publishing, 2017b.

Durand, L. C. A. Left part of the liver. Int. J. Morphol., 36(1):113-20, 2018.

Durand, L. C. A. Liver: Seven hepatic segments. Int. J. Morphol., 34(4):1522-30, 2016.

Durand, L. C. A. Liver: The portal segment V. Int. J. Morphol., 35(1):363-7, 2017 a.

Durand, L. C. A.; Torres, G. C. A. \& Cervera, C. A. Hepatic portal segmentation using reconstructed three-dimensional tomography images. Int. J. Morphol., 35(3):859-63, 2017.

Fasel, J. H.; Selle, D.; Evertsz, C. J.; Terrier, F.; Peitgen, H. O. \& Gailloud, P. Segmental anatomy of the liver: poor correlation with CT. Radiology, 206(1):151-6, 1998.

Federative Committee on Anatomical Terminology (FCAT). Terminologia Anatomica. International Anatomical Terminology. Madrid, Médica Panamericana, 2001.

Fischer, L.; Cardenas, C.; Thorn, M.; Benner, A.; Grenacher, L.; Vetter, M.; Lehnert, T.; Klar, E.; Meinzer, H. P. \& Lamadé, W. Limits of Couinaud's liver segment classification: a quantitative computer-based three-dimensional analysis. $J$. Comput. Assist. Tomogr., 26(6):962-7, 2002.

Hata, F.; Hirata, K.; Murakami, G. \& Mukaiya, M. Identification of segments VI and VII of the liver based on the ramification patterns of the intrahepatic portal and hepatic veins. Clin. Anat., 12(4):229-44, 1999.

Iqbal, S.; Iqbal, R. \& Iqbal, F. Surgical Implications of Portal Vein Variations and Liver Segmentations: A Recent Update. J. Clin. Diagn. Res., 11(2):AE01-AE05, 2017.

Ishibashi, Y.; Sato, T. J.; Hirai, I.; Murakami, G.; Hata, F. \& Hirata, K. Ramification pattern and topographical relationship between the portal and hepatic veins in the left anatomical lobe of the human liver. Okajimas Folia Anat. Jpn., 78(23):75-82, 2001.

Oshiro, Y. \& Ohkohchi, N. Three-Dimensional Liver Surgery Simulation: ComputerAssisted Surgical Planning with Three-Dimensional Simulation Software and Three-Dimensional Printing. Tissue Eng. Part A, 23(11-12):474-80, 2017.

Rieker, O.; Klos, G.; Beckmann, P.; Vomweg, T. W.; Otto, G. \& Thelen, M. Automatic classification of liver segments according to Couinaud: development of a new algorithm and evaluation spiral CT data. Rofo, 175(12):1655-9, 2003.

Rutkauskas, S.; Gedrimas, V.; Pundzius, J.; Barauskas, G. \& Basevicius, A. Clinical and anatomical basis for the classification of the structural parts of liver. Medicina (Kaunas), 42(2):98-106, 2006.

Shilal, P. \& Tuli, A. Anatomical variations in the pattern of the right hepatic veins draining the posterior segment of the right lobe of the liver. J. Clin. Diagn. Res., 9(3):AC08-12, 2015.

Soyer, P.; Bluemke, D. A.; Choti, M. A. \& Fishman, E. K. Variations in the intrahepatic portions of the hepatic and portal veins: findings on helical CT scans during arterial portography. A. J. R. Am. J. Roentgenol., 164(1):103-8, 1995.

Strasberg, S. M.; Belghiti, J.; Clavien, P. -A.; Gadzijev, E.; Garden, J. O.; Lau, W. -Y.; Makuuchi, M. \& Strong, R. W. The Brisbane 2000 Terminology of Liver Anatomy and Resections. $H P B, 2(3): 333-9,2000$.

Corresponding author:

César Augusto Durand López

Roosevelt Av. 6355, Miraflores

Lima 18 - PERÚ

E-mail: cesaraugustoo1@gmail.com 